\title{
Primary Prevention of Childhood Obesity: An Interdisciplinary Analysis
}

\author{
Anja Hilbert ${ }^{\mathrm{a}}$ Jens Ried ${ }^{\mathrm{b}}$ Daniel Schneider ${ }^{c}$ Clemens Juttner ${ }^{\mathrm{d}}$ Marc Sosna ${ }^{\mathrm{e}}$ Peter Dabrock $^{\mathrm{b}}$ \\ Michael Lingenfelder ${ }^{d}$ Wolfgang Voit $^{c}$ Winfried Rief ${ }^{a}$ Johannes Hebebrand ${ }^{f}$ \\ a Department of Psychology, \\ ${ }^{b}$ Department of Protestant Theology/Social Ethics, \\ ${ }^{\mathrm{c}}$ Department of Law, \\ ${ }^{\mathrm{d}}$ Department of Business Administration and Economics, Philipps University of Marburg, Marburg, Germany \\ e IESE Business School, Barcelona, Spain \\ ${ }^{f}$ Department of Child and Adolescent Psychiatry,University of Duisburg-Essen, Essen, Germany
}

\section{Key Words}

Prevention - Risk factors - Behavior modification . Economics - Public policy

\section{Summary}

The primary prevention of childhood obesity requires combined efforts by stakeholders at various societal levels, based on the knowledge from multiple disciplines. The goal of the present study was therefore to analyze current preventive approaches and delineate implications for future prevention research and practice by integrating knowledge from genetics, law, economics, psychology, and social ethics. Inconclusive evidence on the etiology of obesity, a complex, multifactorial condition, likely complicates prevention, leading to a lack of specificity regarding target groups, focus, and techniques. It is recommended to increase the specificity of prevention by explicitly considering risk factor evidence, including evidence on genetic factors. Because the institutional and legal framework of primary obesity prevention in children is insufficient in many countries, considering the risk factors for childhood obesity is also crucial for establishing a basis for legal regulations. Companies from sectors concerned with food intake and physical activity may be involved in preventive action, e.g., for initiating self-defeating sanctions. Long-term behavior change may be enhanced through the systematic application of behavior modification techniques within primary prevention programs. Overall, an interdisciplinary perspective furthers understanding of the complexity of this condition and can inform public health strategies on the primary prevention of childhood obesity.

\section{KARGER}

(C) 2008 S. Karger GmbH, Freiburg

\section{Introduction}

Obesity is an increasingly prevalent risk factor for medical morbidity and mortality as well as impaired quality of life [1]. Recently, the prevention of childhood obesity has been considered a public health priority [2,3], with primary prevention efforts directed towards preventing its initial occurrence as the most salient approach [4-6]. However, specific preventive strategies and interventions remain to be determined [7, 8]. Obesity prevention has emerged as a challenge that requires combined efforts by multiple stakeholders at various societal levels [9], and thus needs to build upon the expertise from several disciplines.

The current study's overarching goal is to use an interdisciplinary perspective to analyze current approaches to the primary prevention of obesity in children under age 18, identify barriers and shortcomings to prevention efforts, and delineate implications for future prevention research and practice. This analysis arises from the experiences of our multidisciplinary research team including geneticists, psychologists, economists, jurists, and ethicists collaborating in the field of obesity. The rationale for combining disciplines is depicted in figure $1 . \mathrm{Ge}$ netic research is mainly aimed at determining the biological predisposition to obesity in relation to environmental influences. Psychological research studies behavioral/environmental risk factors and design of preventive interventions. As opposed to the concentration of genetics and psychology on the individual level, law and economics are both concerned with the environmental, i.e. societal, level of obesity prevention. Law sets the conditions of public health policy, including the funding of prevention through public resources and market guidelines or statutes. Economics is involved because nutrition and physical activity are both influenced by marketing, design, 
and promotion of products (e.g. foods). Furthermore, social ethics considers individual and societal conditions for - and consequences of - prevention. Although deemed to be important [2], most of these disciplines have not been involved frequently in obesity prevention, and their combination in this field is unique. To ensure adequate levels of detail and complexity, other disciplines concerned with the etiology and prevention of obesity (e.g. political science, exercise science, media science, etc.) have not been included within the current context. This perspectives paper therefore sought to provide an example and a conceptual basis for possible further extensions regarding other disciplines and other types of prevention (e.g. secondary prevention), or other target groups (e.g. adults).

By definition, prevention should tackle the risk factors of obesity in order to achieve a reduction of incidence rates, that is, an occurrence of new obese cases [4]. This interdisciplinary analysis will, therefore, be based on summaries of previous prevention and risk factor research, and an evaluation of the relationship between these research fields.

\section{Evidence Base on Primary Prevention of Childhood Obesity}

\section{Previous Prevention Research}

Most empirical evidence available on the primary prevention of childhood obesity is focused on individual behavior change towards healthy nutrition and/or physical activity. The most recent reviews of primary obesity prevention in children identified ten long-term prevention studies with a follow-up period of at least 1 year [5,6]. Most of these studies evaluated universal prevention programs in schools (targeting all children regardless of their risk for obesity), while a few studies provided selective prevention to high-risk groups, for example NativeAmerican children. The core interventions consisted of education and behavior modification regarding nutrition and physical activity, partly in combination with environmental interventions such as improving food choices in school cafeterias, educating parents, or using devices to control television viewing. Overall, there were few effects on body weight (measured by body mass index $\left(\mathrm{BMI}, \mathrm{kg} / \mathrm{m}^{2}\right)$. Long-term effectiveness was documented in only a few prevention trials on childhood obesity [5,6], a finding that was confirmed by a recent metaanalysis on prevention trials documenting weight outcomes in children and young adults [10]. Despite the overall low effectiveness on obesity, several prevention trials have found improvements in attitudes, self-reported behavior, and environmental aspects (e.g. self-esteem, eating behavior, television viewing, or food choice in school cafeterias) [5, 6]. Beyond methodological limitations regarding power, assessment and design, the main limitations of the prevention studies concerned their modest inclusion of high-risk groups (e.g. ethnic

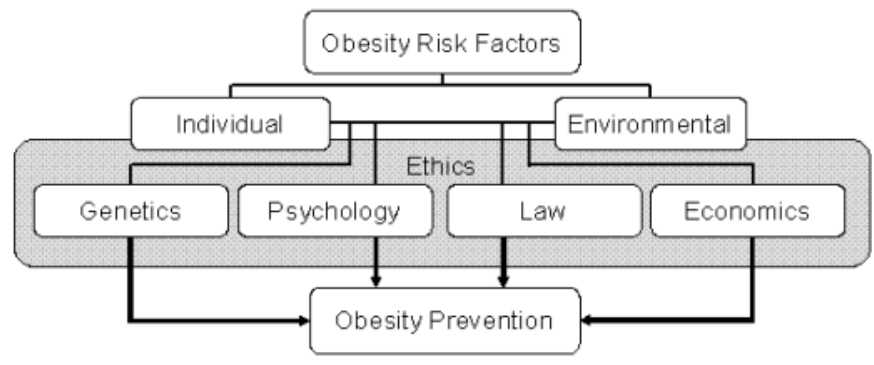

Fig. 1. Rationale for the interdisciplinary analysis on primary prevention of childhood obesity.

minorities or individuals with low socio-economic status), a lack of target-group-specific interventions, a focus on shortterm rather than long-term behavioral change, a lack of theoretical underpinning, and neglect of socio-environmental influences on weight gain. In addition, obesity prevention programs were lacking in areas other than educational settings, such as community settings.

Given the low effectiveness of current individual prevention programs, ecological models of obesity prevention have been proposed, offering a framework for systematic public health programs. Ecological models (e.g. the epidemiological triad [9] or the Structural Model of Health Behavior [11]) share a conceptualization of eating and activity behavior as an interaction between the individual and the environment; consequently, prevention should target both the individual and the environment on various levels through the home, neighborhood, community, school or work settings, health care system, media, transportation, and food sector.

Currently, applications of ecological prevention are rare. Few environmental interventions in the microenvironment (e.g. modifying the activity and nutrition environment in schools or enhancing access to places and facilities for physical activity) have shown an effect on BMI [12]. The familial environment appears particularly important for the prevention of obesity in young children since eating and activity patterns usually develop in a familial context [13], but parental involvement has not been shown to yield any advantage in obesity prevention [10]. Overall, results on the effectiveness of microenvironmental interventions remain inconclusive, and evidence on macroenvironmental interventions is virtually absent.

\section{Previous Research on Risk Factors of Childhood Obesity}

Risk factors for obesity are defined as factors that have a significant association with and precede the onset of obesity (if factors cannot be changed or change spontaneously, they are termed markers). According to this state-of-the-art risk factor definition by Kraemer et al. [14], risk factors can only be identified in longitudinal studies, including randomized controlled trials, genetic studies, or cross-sectional studies using data 
recorded before the onset of obesity. Although cross-sectional studies with concurrent or retrospective assessment can identify correlates of obesity, they cannot establish causality. In order to provide a critical reading of the available evidence, the summary of risk factors of childhood obesity that follows therefore concentrates on findings from longitudinal studies.

\section{Genetic Risk Factors}

In broad terms, obesity likely results from increments in positive energy balance over time caused by various genetic, environmental and individual factors. Concerning the genetic markers of risk, results from twin studies suggest that genetic factors explain $50-80 \%$ of the variance in BMI [15-17]. Family and adoption studies have mostly found lower heritability estimates $(20-80 \%$ [15] or $60 \%$ [17]). These heritability estimates are study-specific and cannot be generalized. In light of the epidemic rise in obesity, it is of interest that no evidence exists to suggest that heritability estimates for BMI have changed over time.

Substantial progress has been made in the molecular elucidation of monogenic forms of obesity $[15,16]$. The clinically most important monogenic form of obesity is due to mutations in the melanocortin-4 receptor gene $(M C 4 R)$, which can be detected in $2-4 \%$ of all extremely obese children $[18,19]$. It is, however, becoming increasingly evident that many gene variants with small effects influence body weight [20, 21]. Two polymorphisms have been detected and meta-analytically confirmed, both with a minor influence on body weight (i.e. the $M C 4 R$ V103I polymorphism and the CC genotype of rs7566605 near the insulin-induced gene 2 [20-22]. Based on technological advances such as DNA chips, future years will undoubtedly witness the identification of additional genes and, potentially, the elucidation of gene-gene and gene-environment interactions.

\section{Environmental and Behavioral Factors}

Secular changes in the environment are assumed to underlie the obesity epidemic. These changes such as increased portion sizes, more fast food restaurants, food marketing that includes increased food advertisements, or heightened availability of labor-saving and entertainment devices [23] likely provide behavioral choices in favor of a positive energy balance. Yet, it has proven difficult to unequivocally pinpoint the relevant environmental/behavioral factors, and prospective evidence is only beginning to emerge [24-26].

One established behavioral risk factor is television viewing, an indicator of a sedentary lifestyle that has longitudinally predicted increased BMI throughout childhood [27-29]. Likewise, reducing the time spent watching television has been found to decrease childhood adiposity [30]. Television viewing co-occurs with exposure to food advertisements and consumption of snack food [31], yet a causal link between exposure to food advertisements, snacking, and obesity has not been clearly established [32]. Longitudinal evidence is emerging that less leisure-time physical activity and higher BMI in adolescence are associated [33].

Concerning energy intake, only inconsistent prospective evidence links energy intake, dietary fat or carbohydrate intake, consumption of energy-dense food, or snack food and soft drink consumption to measures of obesity in adolescents [34-37]; similar inconclusive results were found for other age groups $[25,26]$. Further, depressive symptoms in later childhood and adolescence have been identified as predictive for obesity in later adolescence [38].

Longitudinal associations between low socio-economic status and childhood obesity risk have been shown repeatedly [39-43] although it remains unclear how this marker translates into higher BMI. Of particular note is recent evidence demonstrating a negative impact of low socio-economic status on the outcome of obesity prevention in childhood [44]. Additional childhood markers of obesity risk have been established (e.g. early adiposity rebound, maternal smoking during pregnancy), but it is unclear how these impact energy balance [45].

\section{Discussion of Research on Prevention and Risk Factors in Ethical Perspective}

Overall, there is a lack of conclusive evidence regarding risk factors for childhood obesity. Based on the current literature, it seems reasonable to assume that many environmental and behavioral risk factors exist that may each account for a minor contribution towards higher BMI; depending on the genetic predisposition of a specific individual, a single risk factor (or a combination of these) may have different effects on BMI.

This lack of established risk factors and the etiological complexity likely complicate the primary prevention of childhood obesity and may have contributed to the relative ineffectiveness of previous preventive efforts. If obesity risk factors were clear and if the impact of specific risk factors on BMI was quantified, prevention efforts could be designed to specifically reduce these factors, provided that their effect on BMI is substantial. While this may increasingly prove feasible in the future, a main contention of the present paper is that current preventive approaches could benefit from more explicit consideration of risk factor research.

An individual can only act based on his/her capacities, that is, his/her skills, a certain genetic predisposition, and a given environment. Therefore, it is indicated to first consider implications from genetic risk factor research for obesity prevention as the genetic make-up sets limits and ranges for behavioral and environmental influences on body weight. It is not possible to modify genes, but gene expression may be modified through environmental/behavioral change (see 'Implications of Genetic Findings' below).

Because of the putative interactions between the individual and the environment in the development of obesity, prevention focusing solely on either aspect is likely to be ineffective. 
Therefore, potential environmental interventions (see 'Environmental Implications for Obesity Prevention' below) need, secondly, to be explored, despite a lack of clear risk factor evidence. When considering environmental interventions, it is noted that any preventive effort should aim at - and, ideally, prove effective for - changing individual behavior to achieve better weight maintenance, with the ultimate goal to reduce incidence rates of obesity.

Thirdly, research on the etiology of obesity has clear implications for designing interventions to directly focus on individual behavior change in children. The etiology of obesity is likely specific for individuals and/or groups of individuals with similar risk factor profiles. Since the incomplete etiological evidence precludes standardized approaches, it is indicated to identify and modify the individual or target-group-relevant factors that are associated with a positive energy balance (see 'Psychological Implications: Behavior Modification in the Prevention of Childhood Obesity' below). Furthermore, all prevention programs should focus on decreasing times of watching television, the most well-supported behavioral risk factor for childhood obesity. This focus should, however, not preclude further studies on other novel behavioral targets.

Although behavior change is the target of prevention, this does not imply that one is fully or mainly responsible for one's overweight. For children especially, responsibility for being obese is more attributable to parents than to themselves [46]. In an ethical evaluation of responsibility, individual responsibility refers to the capacities of the person(s), limited by genetic and environmental factors that are not in personal control. Thus, realistically assessing individual risk factors and promoting individual capabilities [47] are also a matter of fairness. For example, consideration of barriers to change that accumulate with low socio-economic status is indispensable in the design of preventive strategies.

\section{Genetic, Environmental, and Behavioral Implications for Primary Prevention of Childhood Obesity}

\section{Implications of Genetic Findings}

Gene/environment interactions, crucial to the development of obesity, likely influence the effects of prevention efforts [48]. A genetic predisposition likely sets limits for behavioral influences on body weight, but also indicates a greater need of preventive action in genetically vulnerable groups. Implications of genetic risk factor research for childhood obesity prevention are as follows.

\section{Identification of High-Risk Groups}

While in the future genetic diagnostic testing may be suited for early identification of monogenic forms of obesity [49] and possibly for oligogenic or polygenic forms, a family history of obesity can currently be interpreted as an indicator of a genet- ic predisposition to obesity on the phenotypical level [17, 40, 50]. Still, a family history of obesity has been considered as a risk indicator in only a few prevention studies [5, 6]. As a family history of obesity is associated with a low socio-economic status, a fact that has been explained through assortative mating [51], a prevention focus on families with obese parents or low socio-economic status or both seems promising.

\section{Critical Periods: Timing of Prevention}

Genetic risk factors predispose to critical or sensitive periods, defined as developmental phases with increased susceptibility to environmental influences [52]. Periods such as infancy, the 'adiposity rebound' in middle childhood, or puberty may constitute sensitive periods for increased body weight. In addition to sensitive periods for weight gain, there may be sensitive periods for the development of eating behavior and physical activity, e.g. for food preferences that have a genetic basis and develop in the first years of life [53]. Consideration of sensitive periods is relevant for timing of preventive measures.

\section{Focus of Prevention: Non-Shared Environment}

The non-shared environment explains a greater amount of variance in obesity than the shared environment $[17,54,55]$, indicating that individual characteristics (e.g. specific peer group) rather than familial characteristics (e.g. familial activity patterns) account for interindividual differences in BMI [56]. Thus, the individual child's eating and activity behavior should be the focus in prevention. However, in early childhood, shared environmental factors are more relevant than in later childhood or adolescence $[57,58]$, and thus, with young children, shared environmental factors should have more of the prevention focus.

\section{Focus of Prevention: Destigmatization}

The obesity stigma, associated with stigmatization and social discrimination of obese persons in various important situations of life, is related to the assumption that obese individuals are responsible for the development and maintenance of their excess weight [59]. Obviously, this assumption underestimates the complex etiology of obesity. Education about genetic and environmental risk factors for obesity that are beyond personal control may have the potential to reduce the stigma of obesity, the conditions of which still need to be further detailed [60]. Yet destigmatization has been considered as a goal in only a few obesity prevention programs [5], and problems remain regarding unintended effects. For example, education about determinants that are not attributable to the individual may decrease motivation for changing one's behavior.

Overall, results from genetic research provide a partial explanation for the low effectiveness of previous prevention programs and can be used as a rationale to increase specificity of preventive measures regarding identification of high-risk groups, timing, goals, and foci of prevention. Future evidence may allow researchers to empirically characterize high-risk 
groups who have strong exposure to genetic and environmental risk factors and/or strong gene/environment interactions, for which prevention with a focus on individual behavior change may need to be augmented (see 'Psychological Implications: Behavior Modification in the Prevention of Childhood Obesity' above) and extended by environmental interventions.

\section{Environmental Implications for Obesity Prevention}

\section{Legal Implications}

On the environmental level, law can set conditions in which a market or a health care system operates. As it is beyond the scope of this paper to comprehensively describe the many international regulations for the primary prevention of childhood obesity, we will discuss current regulations, mainly from Germany and the European Union (EU).

\section{Implementation of Prevention in Health Care Systems}

Various 'National Action Plans against Obesity' for the prevention of childhood obesity have been established in EU member states. Most of these plans include recommendations, guidelines, information about nutrition and physical activity, and educational programs, but they are frequently non-coercive, non-specific, poorly coordinated, and not linked to national health care systems [8].

In Germany, e.g., compulsory health insurance companies are assigned the task of financing preventive interventions. But as this assignment is non-coercive, the insured person is not able to enforce a claim for preventive interventions. Furthermore, several medical prevention guidelines have been devised for prevention procedures in target populations. For instance, these guidelines aim to diagnose childhood diseases early by monitoring physical development with special attention to over- and underweight. Yet implementation of these prevention guidelines is voluntary and poorly coordinated. Therefore, the legislator is planning to extend the health care system through compulsory preventive interventions, although this requires careful consideration of financial resources.

\section{Health Claims and Commercial Regulations}

Many national acts in Europe are a consequence of decisions made at the EU level, in particular those concerning consumer protection. For example, the EU Committee plans to enhance consumer education, especially for children, to ensure adequate knowledge about the connections between nutrition, physical activity, and health [7]. Because children should not be exposed to contradictory messages through parents, teachers and the media, the Committee suggests increased cooperation between different actors such as the health care system, schools, and the food industry. As an initial step, the Committee pleads for voluntary actions by the involved industries as these may be more flexible, fast-acting, and less likely to affect people's constitutional rights than coercive law. Examples for voluntary actions in the USA are the self-defeating sanctions by the soft-drink industry for removal of soft drinks from vending machines in schools, or the fast food campaign for nutrition labeling on fast food packages.

Furthermore, a regulation was recently passed by the EU Council, which constitutes that 'scientific substantiation should be the main aspect to be taken into account for the use of nutrition and health claims' [61]. These claims will have to be permitted by the European Food Safety Authority to avoid misleading the consumer. This applies especially to advertisements targeting children who may not be able to make rational decisions [62], but who have considerable purchase power and influence on parents' buying decisions [63]. However, thus far, courts in Germany judge reluctantly when dealing with cases of deceptiveness. It is assumed that the consumer knows that a product advertised as 'fat-free' or 'fat-reduced' can still be high in sugar and may promote weight gain. Hence, the necessity of warnings (as on cigarette packages) is lessened by referencing to the personal responsibility of the mature consumer without considering that children are not as mature as adults and may need additional protection.

\section{Evaluation of Legal Options}

When reflecting on legal regulations for the purpose of obesity prevention, the rights and interests of the involved parties have to be considered: A benefit gained by one group can mean an infringement of fundamental rights for the other. Therefore it seems difficult to justify legal regulations, especially when risk factor evidence is weak (see 'Discussion of Research on Prevention and Risk Factors in Ethical Perspective' above). Self-restrictions by the relevant industries could therefore be a viable first step. To avoid misleading consumers, including children, the Health Claims Regulation seems to be an adequate instrument. Implementation of preventive procedures in health care systems may be a further important step to coordinate the spectrum of existing approaches to obesity prevention and enhance their effectiveness. Legal regulations such as financial or organizational laws may be necessary, but the potential bureaucratic overhead needs to be considered [64].

\section{Economic Implications}

The rise of obesity has an economic basis as well. For example, a decrease of real food prices (especially of energy-dense food), the promotion of prepackaged food in increasing portion sizes, and the heightened availability of labor-saving and entertainment devices have presumably contributed to the obesity epidemic (see 'Previous Research on Risk Factors of Childhood Obesity' above). Furthermore, the fact that obesity cumulates disproportionately in lower income groups [65] supports the notion that tight individual budget restrictions may result in increased unhealthy food and/or physical activity choices. Therefore, the price of healthy products compared to their unhealthy counterparts moves into the focus of econom- 
Fig. 2. Co-action of income and substitution effects. The amount of money a consumer can spend on food has an effect on the quantity of both 'healthy' and 'unhealthy' food products he or she will buy. If healthier food products are offered at a lower price, the consumer will be able to purchase more of these products. Thus, the decrease of the price of the healthier product reduces the expenditure required to achieve an initial utility level 1 , and a higher utility level 2 can be achieved with the same expenditure. This results in an increase of the consumer's real income. The demand changes can therefore be broken down into two effects indicated by arrows: i) the income effect, which is the change resulting solely from the change in real income; and ii) the substitution effect, which results solely from the change in the price of the healthy product with real income held constant [80].

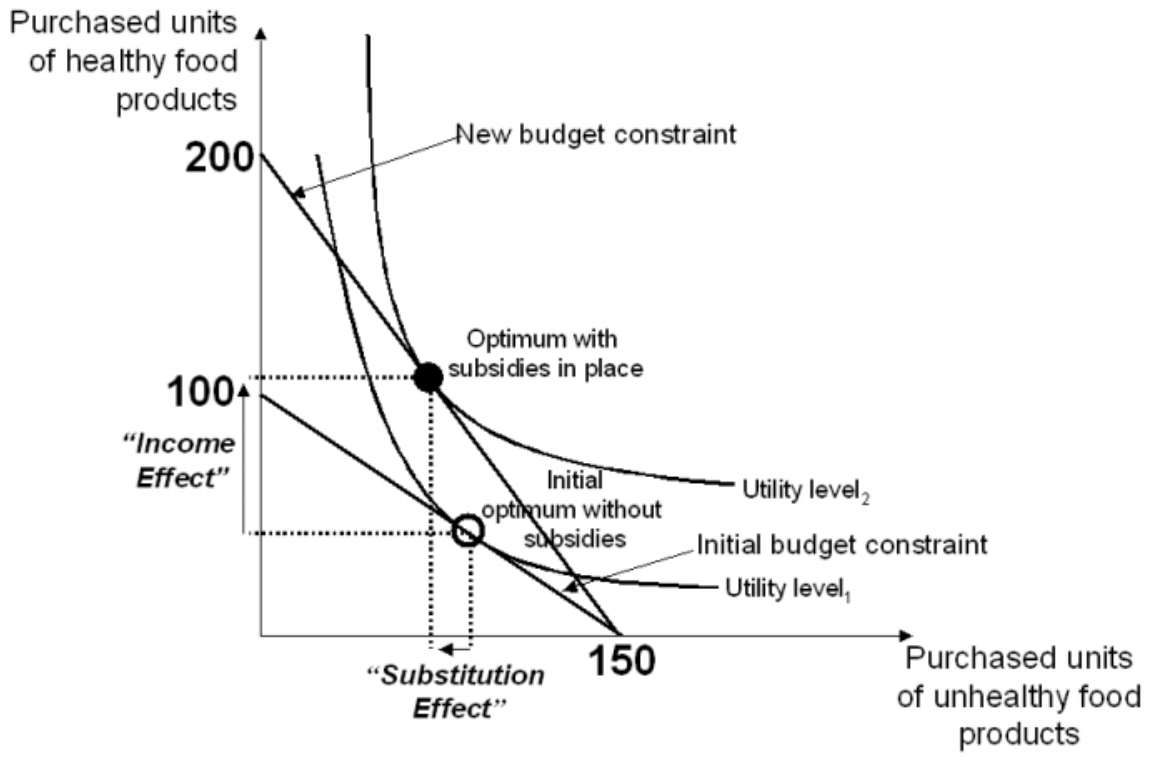

ic approaches towards obesity prevention. As mentioned above, this is especially important as children have increasing consumption power and influence on their parents' and peers' buying decisions.

The discussion on economic options for obesity prevention focuses mainly on two basic tools of intervention regarding the price of a product: taxes and subsidies. Taxes impose costs on economic agents (i.e. parents and/or children) by increasing the price of a product or service, whereas subsidies financially support socially desired products or services.

While it remains unclear what effect taxes would have on children's purchase and eating behavior or physical activity [66], the main question in tax construction is how to define the object to be taxed: Presumably, the most frequently discussed option is to tax food items with regard to their fat content. However, fats may, first, not be equally harmful and thus, should not be treated equally [67]. Second, it is unclear whether increased fat intake is a main cause of obesity (see 'Evidence Base on Primary Prevention of Childhood Obesity' above). Third, such a tax may especially penalize low-income households. It can easily be shown that definitional problems are inherent to such tax constructions and also arise when considering other taxation bases, for example, energy density, specific food types, or maximum percentage of certain ingredients [68, 69]. Evidence-based definitions ranking existing and new products along potential health effects on consumers would be necessary before considering such taxes. In addition, such taxes would likely result in increased bureaucratic effort and attempts by food companies to redesign their products to circumvent the regulation.

At first glance, subsidies seem more promising because the prices of healthy products would decrease through government intervention. From an economic viewpoint, the impact of price changes on consumption can be deconstructed into two effects: the income effect and the substitution effect, as shown in figure 2. In the income effect, if the healthy food becomes cheaper, the income has a greater purchasing power. Individuals have more money than before and can buy more of both healthy and unhealthy foods. As the price of healthy food has fallen, individuals obtain more units of healthy food for every unit of unhealthy food. In the substitution effect, the consumer may buy less unhealthy food and more healthy food because unhealthy food is relatively more expensive. Though a number of problems seen with taxes are avoided with subsidies (e.g., no penalization of low-income families, no loss of consumer sovereignty), the same definitional problems occur, and the administrative effort to handle subsidies is considerable. Furthermore, given financial constraints in the public purse, it is unclear how such subsidies would be financed.

In public health issues like smoking or alcohol consumption, focus has shifted from individual to environmental approaches [70] (see 'Previous Prevention Research' above). As food and beverage producers have a substantial marketing influence on children's daily environments, they need to be involved in obesity prevention. As shown, direct 'command-and-control' instruments like taxes and subsidies bear severe implementation problems. Instead, the focus needs to be shifted to more indirect approaches based on market mechanisms and involvement of the relevant industries. As obesity is currently receiving much public attention, providing 'healthy' products (e.g., foods) is in the interest of companies concerned about their reputation and especially important when defining their future strategies. Once a demand arises from consumers and society, it likely affects the whole food value chain. Network approaches that include companies have already started in several countries (e.g. France (Ensemble, Prévenons l'Obésité Des Enfants) and Germany (Platform Diet and Physical Activity)). The most critical factor in network approaches is managing these multiple stakeholders - each of them with own backgrounds and agendas. 
Fig. 3. Behavior modification: determinants of short- and long-term behavior change (W. Rief et al. - unpublished manuscript).

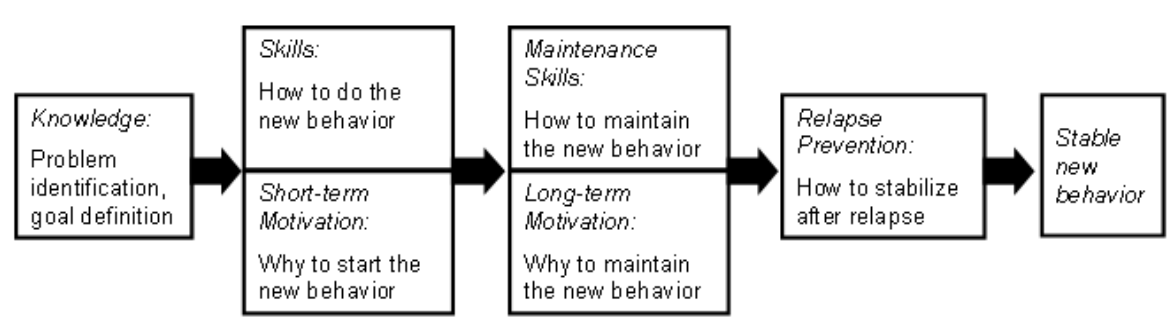

Psychological Implications: Behavior Modification in the Prevention of Childhood Obesity

Behavior modification has been used to promote long-term behavior change in the prevention of many health problems and diseases [71]. Yet in the field of primary prevention of childhood obesity, most studies have been criticized for a lack of systematic application of behavior modification (e.g. a lack of focus on long-term behavior change, neglect of socio-environmental influences of weight gain, and non-specificity regarding target groups). In addition, weight loss treatments using behavior modification have demonstrated short-term efficacy with some evidence for extended persistence in children [72]. Therefore, the current section will discuss how behavior modification can be applied to primary prevention approaches.

In accordance with the general risk formulation of obesity (see 'Previous Research on Risk Factors of Childhood Obesity' above), behavior modification aims at replacing problem behaviors (i.e., overconsumption and/or lack of physical activity) with healthier lifestyle behaviors to allow for long-term weight management. In the acquisition of new habits it is useful to distinguish short-term from long-term behavior change that require different sets of skills and motivation, as depicted in figure 3 .

Because of the etiological complexity of obesity, it seems crucial to adopt an approach aimed at individuals and target groups (see 'Discussion of Research on Prevention and Risk Factors in Ethical Perspective' above). Thus, a prerequisite to behavior modification is the identification of individual problem behavior of the child or, for young children, of the parent, and the related individual and socio-environmental development factors. In an individual or group-specific behavior analysis, the nature of the problem behavior (e.g. emotional eating), maintenance variables (e.g. absence of regular meals), and reinforcers (e.g. relaxation) can be identified [73]. Identification of resources ('capabilities') appears central to behavior change, that is, building upon personal strengths such as peer support [74] (see 'Discussion of Research on Prevention and Risk Factors in Ethical Perspective' above).

Furthermore, it is essential to determine motivators for behavior change [75] derived from personal interests and preferences. For example, as opposed to adults, children may not be motivated to change their diet and/or physical activity behav- ior for health reasons; instead, incentives for behavior change in which a child is interested (e.g. ringtones for mobile phones) are likely to be more effective reinforcers. Strategies for motivational enhancement in the long term include establishing public interest for change, providing long-term support for stabilization of change, and establishing new behaviors as habits by linking them to daily activities. In addition, it is helpful to distinguish intrinsic motivation achieved through internal attitudes and convictions such as self-efficacy beliefs from extrinsic motivation achieved through toys, tokens, or external praise from others [76]. As long-term maintenance of change is more readily achieved through intrinsic than through extrinsic motivation, intrinsic motives need to be identified and enhanced. Because significant others such as parents or teachers likely play an important role in supporting behavior change, it is also worthwhile to consider enhancing their motivation through training or public recognition.

In goal-setting, a limited set of simple goals is usually preferable to a greater number of more complex goals [10]. It is recommended to focus on the general goal of decreasing sedentary activity/increasing physical activity (see 'Discussion of Research on Prevention and Risk Factors in Ethical Perspective' above), as well as a few individually tailored goals. Goals need to be defined through specific behavior that is not compatible with the problem behavior, for example, active play times before TV watching is allowed, both with a fixed duration. Goals should be achievable and sustainable in the long term in order to enhance self-efficacy, an established predictor of weight loss maintenance [77]. It is important to note that self-efficacy is more likely to be fostered if the problem behavior is destigmatized. Anticipating and destigmatizing potential relapse into problem behavior could prevent lowered motivation and abandoning the lifestyle change.

In general, it is recommended to develop manualized and structured behavioral approaches, both for quality assurance reasons and for easier dissemination. On this basis, future prevention trials could determine preventive components that are effective for specific target groups. In addition to in-depth applications in selective prevention, behavior modification can be disseminated in a cost-effective manner through universal prevention programs (e.g. within school health curricula); here, material and training of providers need to be given. As shown with prevention efforts in other domains, emphasis needs to be placed on interactive rather than purely didactic 
strategies, for example, guided discovery [10]. Overall, prevention should be tailored not only to the individual and his/her significant others, but also should take into account settings likely influencing individual eating and activity behavior (e.g. neighborhood walkability; see 'Previous Research on Risk Factors of Childhood Obesity' above). It is also important to consider stakeholder participation in a prevention network including peers, family, institutions, politicians, and research groups (see 'Environmental Implications for Obesity Prevention' above).

This description of behavior modification principles can be used for the evaluation of prevention programs to ensure optimal implementation. Yet whether or not systematic implementation actually decreases incidence rates of obesity in children still needs to be demonstrated.

\section{Discussion}

By integrating knowledge from the disciplines of genetics, law, economics, psychology, and social ethics, this interdisciplinary analysis of primary prevention of childhood obesity demonstrated several conclusions. Obesity prevention on various societal levels is likely complicated by a lack of evidence on the etiology of obesity. As the evidence on behavioral risk factors is inconclusive and genetic and environmental factors are only starting to be determined, previous prevention efforts almost exclusively focused on changing individual behavior. However, these programs were criticized for lack in specificity regarding target groups, focus and techniques of prevention, and their resulting low long-term success. Given the urgency and significance of the obesity problem that requires immediate and effective solutions, it is recommended that the various existing and developing prevention programs are evaluated to ensure orientation at current risk factor research. Based on the current analysis, it appears particularly relevant to consider genetic obesity risk to increase the specificity of prevention, e.g., using a family history of obesity as phenotypical indicator of genetic obesity risk. A family history of obesity also coincides with low socioeconomic status, another well-established marker of obesity risk. Furthermore, it is important to evaluate prevention programs for systematic application of behavior modification techniques and consideration of individual risk factors and capabilities to ensure promotion of long-term behavior change that leads to weight maintenance and a reduction of incidence rates of obesity. In addition, more longitudinal risk factor evidence is warranted to inform future preventive approaches.

In many countries, the institutional and legal framework of obesity prevention requires further examination, as there is frequently short-term rather than sustainable long-term funding, a lack of coordination between multiple stakeholders, and insufficient implementation of prevention efforts in the health care system. Evidence on risk factors for obesity is also crucial to inform network approaches and to justify restrictive legal options for the purpose of prevention. Here, self-defeating sanctions of the relevant industries may be a viable first step towards obesity prevention. Moreover, these industries may be more fundamentally involved in obesity prevention. As taxes or subsidies are limited in feasibility, relevant industries could be involved in the design and promotion of 'healthy' products, stimulating greater request of such products. Network approaches appear suited to involve companies and other relevant stakeholders of prevention efforts on childhood obesity. These approaches require societal conscience about the severity of the obesity problem in children and its multifactorial etiology; currently, however, genetic factors and environmental factors tend to be publicly ignored [78].

Furthermore, neglecting genetic and environmental risk factors is likely associated with the prevalent stigmatization of obese persons that is based on the assumption that obesity develops solely through individual failure. Recognizing the multifactorial etiology of obesity and acknowledging that weight regulation is only somewhat within personal responsibility may therefore shift away from blaming obese individuals towards a more realistic and less stigmatizing understanding of this condition. In fact, responsibility for the development of obesity and the prevention of weight gain lies in multiple areas: law, policy, industry, health care institutions, medical professions, and the individual all should contribute to obesity prevention.

In addition, the present analysis suggests that obesity should be approached not only directly, but also indirectly: An inverse social gradient has been observed in obesity and associated health problems. Therefore, it appears fruitful to initiate a general discussion about social inequality and potential economic, educational, or social interventions for the prevention of obesity and related health problems [79]. Such an indirect approach again requires integration of different perspectives and would thus need to be multidisciplinary. It is yet of note that multidisciplinary work is a challenge in itself: It requires establishment of a common method and language that can be used by all cooperating disciplines in order to provide a systematic basis of joint preventive action.

Overall, the current analysis shows that an interdisciplinary perspective furthers understanding of the complexity of this condition and can inform public health strategies on obesity. Future multidisciplinary work will need to build upon knowledge from further disciplines concerned with obesity risk or prevention or both, such as public health, nutrition, or political sciences, in order to generate structured, comprehensive and fair solutions to this complex childhood condition.

\section{Competing Interests}

None declared. 


\section{Authors' Contributions}

$\mathrm{AH}, \mathrm{PD}, \mathrm{WR}$, and JH conceived the idea of the paper in collaboration with WV and ML. All authors were involved determining the main contents of the article. AH, JR, DS, CJ, MS, WR, and JH drafted the manuscript. PD, ML, and WV supervised writing and critically reviewed the article in collaboration with WR and JH. All authors read and approved the final manuscript.

\section{Acknowledgements}

AH, JR, and DS are supported by educational grant 01GP0491 from the German Ministry of Education and Research. JH is supported by the German National Genome Research Network.

\section{References}

1 Haslam DW, James WPT: Obesity. Lancet 2005;366: 1197-1209.

2 Lobstein T, Baur L, Uauy R, for the IASO International Obesity Task Force: Obesity in children and young people: a crisis in public health. Obes Rev 2004;5:4-104.

3 Koplan JP, Liverman CT, Kraak VI: Committee on Prevention of Obesity in Children and Youth: Preventing childhood obesity: health in the balance: executive summary. J Am Diet Assoc 2005;105: 131-138.

4 World Health Organization: Health Promotion Glossary. Geneva, 1998. www.who.int/hpr/NPH/ docs/hp_glossary_en.pdf.

5 Summerbell CD, Waters E, Edmunds LD, Kelly S, Brown T, Campell KJ: Interventions for preventing obesity in children. Cochrane Database Syst Rev 2005;3:CD001871.

6 Flodmark CE, Marcus C, Britton M: Interventions to prevent obesity in children and adolescents: systematic literature review. Int J Obes 2006;30: 579-589.

7 Commission of the European Communities: Promoting healthy diets and physical activity: a European dimension for the prevention of overweight, obesity and chronic diseases. Luxembourg, 2005 http://ec.europa.eu/ health/ph_determinants/life_ style/nutrition/documents/nutrition_gp_en.pdf.

8 Widhalm K, Fussenegger D: Actions and programs of European countries to combat obesity in children and adolescents: a survey. Int J Obes 2005;29: 130-135.

9 Swinburn B, Egger G: Preventive strategies against weight gain and obesity. Obes Rev 2002;3:289-301.

10 Stice E, Shaw H, Marti CN: A meta-analytic review of obesity prevention programs for children and adolescents: the skinny on interventions that work. Psychol Bull 2006;132:667-691.

11 Cohen DA, Scribner RA, Farley TA: A structural model of health behavior: a pragmatic approach to explain and influence health behaviors at the population level. Prev Med 2000;30:146-154.

12 Sallis JF, McKenzie TL, Conway TL, Elder JP, Prochaska JJ, Brown M, Zive MM, Marshall SJ, Alcaraz JE: Environmental interventions for eating and physical activity. Am J Prev Med 2003;24: 209-217.

13 Davison KK, Birch LL: Childhood overweight: a contextual model and recommendations for future research. Obes Rev 2001;2:159-171.

14 Kraemer HC, Kazdin AE, Offord DR, Kessler RC, Jensen PS, Kupfer DJ: Coming to terms with the terms of risk. Arch Gen Psychiatry 1997;54: 337-343.

15 Hebebrand J, Friedel S, Schäuble N, Geller F, Hinney A: Perspectives: molecular genetic research in obesity. Obes Rev 2003;4:139-146.

16 Bell CG, Walley AJ, Froguel P: The genetics of human obesity. Nat Rev Genet 2005;6:221-234.
7 Maes HH, Neale MC, Eaves LJ: Genetic and environmental factors in relative body weight and human adiposity. Behav Genet 1997;27:325-351.

18 Farooqi IS, Keogh JM, Yeo GSH, Lank EJ, Cheetham T, O'Rahilly S: Clinical spectrum of obesity and mutations in the melanocortin 4 receptor gene. N Engl J Med 2003;348:1085-1095.

19 Dempfle A, Hinney A, Heinzel-Gutenbrunner M, Raab M, Geller F, Gudermann T, Schäfer H, Hebebrand J: Large quantitative effect of melanocortin4 receptor gene mutations on body mass index. J Med Genet 2004;41:795-800.

20 Geller F, Reichwald K, Dempfle A, Illig T, Vollmert C, Herpertz S, Siffert W, Platzer M, Hess C, Gudermann T, Biebermann H, Wichmann HE, Schäfer H, Hinney A, Hebebrand J: Melanocortin-4 receptor gene variant I103 is negatively associated with obesity. Am J Hum Genet 2004;74:572-581.

21 Herbert A, Gerry NP, McQueen MB, Heid IM, Pfeufer A, Illig T, Wichmann HE, Meitinger T, Hunter D, Hu FB, Colditz G, Hinney A, Hebebrand J, Koberwitz K, Zhu X, Cooper R, Ardlie K, Lyon $\mathrm{H}$, Hirschhorn JN, Laird NM, Lenburg ME, Lange C, Christman MF: A common genetic variant is associated with adult and childhood obesity. Science 2006;312:279-283.

22 Hinney A, Schmidt A, Nottebom K: Several mutations in the melanocortin-4 receptor gene including a nonsense and a frameshift mutation associated with dominantly inherited obesity in humans. J Clin Endocrinol Metab 1999;84:1483-1486.

23 Jeffery RW, Utter J: The changing environment and population obesity in the United States. Obes Res 2003;11(suppl):12S-22S.

24 Parsons TJ, Power C, Logan S, Summerbell CD: Childhood predictors of adult obesity: a systematic review. Int J Obes Relat Metab Disord 1999;23: $1-107$

25 Rennie KL, Johnson L, Jebb SA: Behavioural determinants of obesity. Best Pract Res Clin Endocrinol Metab 2005;19:343-358.

26 Rodriguez G, Moreno LA: Is dietary intake able to explain differences in body fatness in children and adolescents? Nutr Metab Cardiovasc Dis 2006;16: 294-301.

27 Hancox RJ, Milne BJ, Poulton R: Association between child and adolescent television viewing and adult health: a longitudinal birth cohort study. Lancet 2004;364:257-262.

28 Marshall SJ, Biddle SJ, Gorely T, Cameron N, Murdey I: Relationships between media use, body fatness and physical activity in children and youth: a meta-analysis. Int J Obes Relat Metab Disord 2004;28:1238-1246.

29 Reilly JJ, Armstrong J, Dorosty AR, Emmett PM, Ness A, Rogers I, Steer C, Sherriff A, for the Avon Longitudinal Study of Parents and Children Study Team: Early life risk factors for obesity in childhood: cohort study. BMJ 2005;330:1357-1363.
30 Robinson TN: Reducing children's television viewing to prevent obesity. JAMA 1999;27:1561-1567.

31 Caroli M, Argentieri L, Cardone M, Masi A: Role of television in childhood obesity prevention. Int J Obes Relat Metab Disord 2004:28:104-108.

32 Lobstein T, Dibbs S: Evidence of a possible link between obesogenic food advertising and child overweight. Obes Rev 2005;6:203-208

33 Kimm SY, Glynn NW, Obarzanek E, Kriska AM, Daniels SR, Barton BA, Liu K: Relation between the changes in physical activity and body-mass index during adolescence: a multicentre longitudinal study. Lancet 2005;366:301-307.

34 Phillips SM, Bandini LG, Naumova EN, Cyr H, Colclough S, Dietz WH, Must A: Energy-dense snack food intake in adolescence: longitudinal relationship to weight and fatness. Obes Res 2004;12: 461-472.

35 Magarey AM, Daniels LA, Boulton TJ, Cockington RA: Does fat intake predict adiposity in healthy children and adolescents aged 2-15 y? A longitudinal analysis. Eur J Clin Nutr 2001;55:471-481.

36 Berkey CS, Rockett HR, Field AE, Gillman MW, Colditz GA: Sugar-added beverages and adolescent weight change. Obes Res 2004;12:778-788.

37 Field AE, Austin SB, Gillman MW, Rosner B, Rockett HR, Colditz GA: Snack food intake does not predict weight change among children and adolescents. Int J Obes Relat Metab Disord 2004;28: 1210-1216.

38 Goodman E, Whitaker RC: A prospective study of the role of depression in the development and persistence of adolescent obesity. Pediatrics 2002;110: 497-504.

39 Bergmann KE, Bergmann RL, Von Kries R, Böhm O, Richter R, Dudenhausen JW, Wahn U: Early determinants of childhood overweight and adiposity in a birth cohort study: role of breast-feeding. Int J Obes Relat Metab Disord 2003;27:162-172.

40 Berkowitz RI, Stallings VA, Maislin G, Stunkard AJ: Growth of children at high risk of obesity during the first $6 \mathrm{y}$ of life: implications for prevention. Am J Clin Nutr 2005;81:140-146.

41 Baltrus PT, Everson-Rose SA, Lynch JW, Raghunathan TE, Kaplan GA: Socioeconomic position in childhood and adulthood and weight gain over 34 years: the Alameda County Study. Ann Epidemiol 2007;17:608-614.

42 Kristensen PL, Wedderkopp N, Moller NC, Andersen LB, Bai CN, Froberg K: Tracking and prevalence of cardiovascular disease risk factors across socio-economic classes: a longitudinal substudy of the European Youth Heart Study. BMC Public Health 2006;6:20

43 Valerio G, D'Amico O, Adinolfi M, Munciguerra A, D'Amico R, Franzese A: Determinants of weight gain in children from 7 to 10 years. Nutr Metab Cardiovasc Dis 2006;16:272-278.

Hilbert/Ried/Schneider/Juttner/Sosna/ Dabrock/Lingenfelder/Voit/Rief/Hebebrand 
44 Müller MJ, Danielzik S, Landsberg B, Pust S: Interventions to prevent overweight in children. Int $\mathrm{J}$ Vitam Nutr Res 2006;76:225-229.

45 Keith SW, Redden DT, Katzmarzyk PT, Boggiano MM, Hanlon EC, Benca RM, Ruden D, Pietrobelli A, Barger JL, Fontaine KR, Wang C, Aronne LJ, Wright SM, Baskin M, Dhurandhar NV, Lijoi MC, Grilo CM, DeLuca M, Westfall AO, Allison DB: Putative contributors to the secular increase in obesity: exploring the roads less traveled. Int J Obes 2006;30:1585-1594.

46 Lotz M: Childhood obesity and the question of parental liberty. J Soc Phil 2004;35:288-303.

47 Dabrock P: Capability-Approach und Decent Minimum: Befähigungsgerechtigkeit als Kriterium möglicher Priorisierung im Gesundheitswesen. Zeitschrift für Evangelische Ethik 2001;46:202-215.

48 Uusitupa M: Gene-diet interaction in relation to the prevention of obesity and type 2 diabetes: evidence from the Finnish Diabetes Prevention Study. Nutr Metab Cardiovasc Dis 2005;15:225-233.

49 Carrel AL, Myers SE, Whitman BY, Allen DB: Sustained benefits of growth hormone on body composition, fat utilization, physical strength and agility, and growth in Prader-Willi syndrome are dosedependent. J Pediatr Endocrinol Metab 2001;14: 997-1105.

50 Mamun AA, Lawlor DA, O'Callaghan MJ, Williams GM, Najman JM: Family and early life factors associated with changes in overweight status between ages 5 and 14 years: findings from the Mater University Study of Pregnancy and its outcomes. Int J Obes 2005;29:475-482.

51 Hebebrand J, Wulftange H, Goerg T, Ziegler A, Hinney A, Barth N, Mayer H, Remschmidt H: Epidemic obesity: are genetic factors involved via increased rates of assortative mating? Int J Obes Relat Metab Disord 2000;24:345-353.

52 Pinel JPJ: Biopsychology. Needham Heights, Allyn and Bacon, 2000.

53 Benton D: Role of parents in the determination of the food preferences of children and the development of obesity. Int J Obes Relat Metab Disord 2004;28:858-869.
54 Hebebrand J, Sommerlad C, Geller F, Gorg T, Hinney A: The genetics of obesity: practical implications. Int J Obes Relat Metab Disord 2001;25: $10-18$.

55 Stunkard AJ, Harris JR, Pedersen NL, McClearn GE: The body mass index of twins who have been reared apart. N Engl J Med 1990;222:1483-1487.

56 Hewitt JK: The genetics of obesity: what have genetic studies told us about the environment. Behav Genet 1997;27:353-358.

57 Pietilainen KH, Kaprio J, Rasanen M, Rissanen A, Rose RJ: Genetic and environmental influences on the tracking of body size from birth to early adulthood. Obes Res 2002;10:875-884.

58 Segal NL, Allison DB: Twins and virtual twins: bases of relative body weight revisited. Int J Obes Relat Metab Disord 2002;26:437-441.

59 Puhl RM, Brownell KD: Bias, discrimination, and obesity. Obes Res 2001;9:788-805.

60 Puhl RM, Schwartz MB, Brownell KD: Impact of perceived consensus on stereotypes about obese people: a new approach for reducing bias. Health Psychol 2005;24:517-525.

61 Commission of the European Communities: Regulation of the European Parliament and of the council on nutrition and health claims made on foods. Luxembourg, 2003. http://europa.eu.int/eur-lex/en/ com/pdf/2003/com2003_0424en01.pdf.

62 Hastings G, Stead M, McDermott L, Forsyth A, MacKintosh AM, Rayner M, Godfrey C, Caraher M, Angus K: Review of research on the effects of food promotion to children: final report. Center for Social Marketing, University of Strathclyde, 2003. www.foodstandards.gov.uk/multimedia/pdfs/foodpr omotiontochildren1.pdf.

63 Story M, French SA: Food advertising and marketing directed at children and adolescents in the US. Int J Behav Nutr Phys Act 2004;1:3.

64 Hebebrand J, Dabrock P, Lingenfelder M, Mand E, Rief W, Voit W: Ist Adipositas eine Krankheit interdisziplinäre Perspektiven. Dtsch Ärztebl 2005; 101:2468-2474

65 Drewnowski A: Fat and sugar: an economic analysis. J Nutr 2003;133:838-840

66 Nugent AP: The metabolic syndrome. Nutr Bull 2004:29:36-43.
67 Astrup A: Dietary fat is a major player in obesity but not the only one. Obes Rev 2001;3:57-58.

68 Strnad J: Conceptualizing the 'Fat Tax': the role of food taxes in developed economies. S Cal L Rev 2005;78:1221-1326.

69 Leicester A, Windmeijer F: The 'Fat Tax': economic incentives to reduce obesity. IFS Briefing Note 2004;49:6-7.

70 Dorfman L, Wallack L, Wodruff K: More than a message: framing public health advocacy to change corporate practices. Health Educ Behav 2005;32: 320-336.

71 Durlak JA: Effective prevention and health promotion programming; in Gullotta TP, Blomm B (eds): Encyclopaedia of Primary Prevention and Health Promotion. New York, Kluwer Academic Plenum Publishers, 2003, pp 61-69.

72 Wilfley DE, Tibbs TL, Van Buren DJ, Reach KP, Walker MS, Epstein LH: Lifestyle interventions in the treatment of childhood overweight: a meta-analytic review of randomized controlled trials. Health Psychol 2007;26:521-532.

73 Kanfer FH, Reinecker H, Schmelzer D: Selbstmanagement-Therapie. Berlin, Springer, 2000.

74 Gassmann D, Grawe K: General change mechanisms: the relation between problem activation and resource activation in successful and unsuccessful therapeutic interactions. Clin Psychol Psychother 2006;13:1-11.

75 Bandura A: Social Foundations of Thought and Action: A Social Cognitive Theory. Englewood Cliffs, Prentice-Hall, 1986.

76 Eccles JS, Wigfield A: Motivational beliefs, values, and goals. Ann Rev Psychol 2002;53:109-132.

77 Teixeira PJ, Going SB, Sardinha LB, Lohman TG: A review of psychosocial pre-treatment predictors of weight control. Obes Rev 2005;6:43-65.

78 Hilbert A, Rief W, Braehler E: What determines public support of obesity prevention? J Epidemiol Community Health 2007;61:585-590.

79 Müller MJ, Danielzik S: Childhood overweight: is there need for a new societal approach to the obesity epidemic? Obes Rev 2007;8:87-90.

80 Gravelle H, Rees R: Microeconomics. Upper Saddle River, Prentice Hall, 2004. 